\title{
PENGARUH PERPUTARAN PERSEDIAAN DAN PERPUTARAN HUTANG TERHADAP SOLVABILITAS.
}

\author{
Dyah Ayu Retno Inten \\ Fakultas Ekonomi Universitas Krisnadwipayana \\ Jalan Unkris Jatiwaringin Jakarta Timur
}

\begin{abstract}
This research was conducted in manufacturing companies listed on the Indonesia Stock Exchange in the 2016-2018 period. The research instrument this time is secondary data in the form of annual financial statements from the company. The population of this research is all manufacturing companies listing on the Indonesia Stock Exchange in 20162018, with a total population of 158 companies. Samples taken as many as 89 companies using purposive sampling. The results obtained from this study are inventory turnover variables have an influence on solvency. The variable Payable turnover has a negative effect on solvability.
\end{abstract}

Keyword: Inventory turnover, Payable turnover and Solvability.

\section{PENDAHULUAN}

Faktor penting dalam suatu perusahaan adalah struktur modal, karena baik buruknya struktur modal mempunyai efek langsung kepada keuangan perusahaan, terutama dengan adanya hutang yang sangat besar akan memberikan beban kepada perusahaan. Dalam hal ini penentuan struktur modal dapat membantu perusahaan dalam menargetkan tingkat hutang secara strategis. Rasio solvabilitas sangat membantu dan menguntungkan bagi pihak manajemen maupun investor untuk memahami bagaimana tingkat struktur modal pada perusahaan, karena perusahaan dengan rasio solvabilitas yang tinggi dapat memberikan dampak timbulnya sebuah resiko besar keuangan perusahaan. Akan tetapi perusahaan dengan rasio solvabilitas yang tinggi dapat memiliki sebuah peluang dalam memperoleh laba yang besar. Setiap perusahaan akan membuat suatu kebijakan mengenai masalah struktur modal. Untuk tiap bagian dari struktur modal ini memiliki resiko biaya modal. Pada saat menggunakan modal sendiri maka resiko perusahaan yaitu wajib membagikan laba yang diperoleh. Sedangkan jika perusahaan memperoleh dana dengan cara meminjam atau berasal dari hutang, maka resiko perusahaan yaitu membayar bunga atas pinjaman tersebut. Namun apabila dana hasil pinjaman tersebut digunakan secara efektif dan efisien dengan membeli aset produktif tertentu atau untuk membiayai ekspansi bisnis perusahaan, hal ini akan memberikan peluang yang besar bagi perusahaan untuk meningkatkan hasil usahanya. Oleh karena itu perusahaan harus

Copyright (c) 2020 Dyah Ayu Retno Inten, SE., M.Si.

This work is licensed under a Creative Commons Attribution-NonCommercial-ShareAlike 4.0 International License. 
meminimalkan biaya modal yang ditanggung.

Rasio yang digunakan untuk mengukur nilai asset perusahaan yang dibiayai dengan hutang merupakan rasio solvabilitas atau rasio leverage. Dengan kata lain, rasio solvabilitas atau rasio leverage merupakan rasio yang digunakan untuk mengukur seberapa besar beban hutang yang harus ditanggung perusahaan dalam rangka pemenuhan asset. Struktur modal dan rasio solvabilitas memiliki hubungan yang sangat penting bagi suatu perusahaan dalam mengukur sejauh mana perusahaan dibiayai oleh hutang. Rasio solvabilitas sangat membantu dan menguntungkan bagi pihak manajemen maupun investor untuk memahami bagaimana tingkat struktur modal pada perusahaan, karena perusahaan dengan rasio solvabilitas yang tinggi dapat memberikan dampak timbulnya sebuah resiko besar keuangan perusahaan. Akan tetapi perusahaan dengan rasio solvabilitas yang tinggi dapat memiliki sebuah peluang dalam memperoleh laba yang besar.

Dalam aktivitas suatu perusahaan agar mendapatkan laba yang maksimal, manajer keuangan perlu mengetahui faktor-faktor yang memiliki pengaruh besar terhadap solvabilitas perusahaan. Dengan mengetahui pengaruh dari masingmasing faktor terhadap solvabilitas, perusahaan dapat menentukan langkah untuk mengatasi masalahmasalah dan meminimalisir dampak negatif yang timbul. Faktor-faktor yang mempengaruhi solvabilitas adalah pengelolaan persediaan secara efektif dan pengelolaan hutang, keduanya merupakan aktivitas perusahaan dalam mengefektifkan modal kerja. Modal kerja merupakan modal atau dana yang digunakan oleh perusahaan untuk membiayai kegiatan operasional yang perputaran kasnya kurang dari satu tahun melalui hasil penjualan produksinya.

Untuk menentukan seberapa efektif persediaan yang dikelola yaitu dengan cara membandingkan antara jumlah harga pokok penjualan dengan rata-rata persediaan dalam satu periode digunakan rasio perputaran persediaan. Pada rasio perputaran persediaan ini menunjukkan kualitas persediaan serta merupakan indikator yang baik dan sangat efektif bagi kemampuan manajemen dalam melakukan aktivitas penjualan. Rasio perputaran persediaan dihitung dengan hasil bagi antara harga pokok penjualan dengan rata-rata persediaan, semakin tinggi rasio perputaran persediaan maka menunjukkan semakin kecil modal kerja yang tertanam dalam persediaan barang dagang. Hal ini merupakan hal yang baik bagi perusahaan, karena jika persediaan barang dagang mampu dijual dalam jangka waktu yang singkat maka perusahaan tidak perlu terlalu lama menunggu dananya yang tertanam dalam persediaan barang dagang untuk dapat dicairkan menjadi uang kas, semakin tinggi rasio perputaran persediaan maka semakin lancar persediaan perusahaan, dan hal ini akan mengakibatkan semakin tinggi tingkat pengembalian investasi pada perusahaan.

Copyright (c) 2020 Dyah Ayu Retno Inten, SE., M.Si.

This work is licensed under a Creative Commons Attribution-NonCommercial-ShareAlike 4.0 International 
Sebaliknya, jika semakin rendah rasio perputaran persediaan maka semakin besar modal kerja yang tertanam dalam persediaan barang dagang, maka hal tersebut tidak baik bagi perusahaan, karena jika persediaan barang dagang tidak mampu dijual dalam waktu yang singkat maka perusahaan butuh waktu yang cukup lama untuk dicairkan menjadi uang kas. Semakin rendah perputaran persediaan maka semakin banyak persediaan yang numpuk digudang maka semakin lambat dan rendah tingkat pengembalian investasi pada perusahaan. Dalam mengelola persediaan barang dagang ini perusahaan bisa menerapkan berbagai metode, salah satunya menggunakan metode rata-rata tertimbang (Average). Metode penilaian persediaan ini merupakan metode yang digunakan untuk menghitung biaya per unit persediaan berdasarkan rata-rata tertimbang dari unit yang serupa dan biaya unit yang dibeli selama suatu periode. Dimana dilakukan dengan cara membagi biaya semua barang yang tersedia untuk dijual dengan unit yang tersedia untuk dijual.

Perputaran hutang merupakan suatu ukuran kemampuan perusahaan dalam melunasi hutangnya, ukuran tersebut menunjukkan kepada investor berapa kali per periode perusahaan membayar jumlah hutang rata-rata, dengan kata lain rasio perputaran hutang adalah berapa kali perusahaan dapat melunasi saldo hutang rata-rata selama tahun berjalan. Hutang dagang dapat menghasilkan tambahan modal, apabila pembayaran hutang dagang di perlama, maka tambahan modal yang dimiliki dapat digunakan untuk melakukan investasi, sehingga perusahaan dapat melakukan kegiatan produksi dengan lebih efektif. Adanya efektivitas ini maka akan mempengaruhi perusahaan dalam meningkatkan kemampuanya untuk menghasilkan laba, dan memenuhi kewajibannya dalam melunasi hutangnya pada pemasok atau vendor. Berdasarkan uraian diatas maka yang menjadi masalah dalam penelitian ini adalah

1. Bagaimana pengaruh perputaran persediaan terhadap solvabilitas ?

2. Bagaimana pengaruh perputaran hutang terhadap solvabilitas?

3. Bagaimana pengaruh perputaran persediaan dan perputaran hutang terhadap solvabilitas?

\section{LANDASAN TEORI}

\section{Persediaan}

Menurut Anggraini (2017) menyatakan bahwa Persediaan (inventory) adalah suatu istilah umum yang menunjukkan segala sesuatu atau sumber daya-sumber daya organisasi yang disimpan dalam antisipasinya terhadap pemenuhan permintaan. Sedangkan menurut Anwar \& Karamoy (2014) menyatakan bahwa Persediaan (inventory) adalah pos-pos aktiva yang dimiliki oleh perusahaan untuk dijual dalam operasi bisnis normal, atau barang yang akan digunakan atau dikomsumsi investasi dalam persediaan merupakan aktiva lancar

Copyright (c) 2020 Dyah Ayu Retno Inten, SE., M.Si.

This work is licensed under a Creative Commons Attribution-NonCommercial-ShareAlike 4.0 International License. 
paling besar dari perusahaan barang dagang dan manufaktur.

\section{Perputaran Persediaan (Inventory Turn Over)}

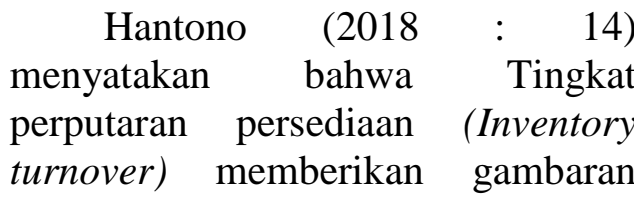
berapa kali persediaan barang dijual dan diadakan kembali setiap periode akuntansi. Perputaran persediaan merupakan rasio yang digunakan untuk mengukur berapa kali dana yang tertanam dalam persediaan akan berputar dalam satu periode atau berapa lama (dalam hari) ratarata persediaan tersimpan di gudang hingga akhirnya terjual. Hery (2017 : 182). Metode rasio perputaran persediaan ini sangat menunjukkan kualitas persediaan barang dagangan dari kemampuan manajemen dalam melakukan aktivitas penjualan dalam meningkatkan efektivitas pengelolaan persediaan. Dengan kata lain rasio ini menggambarkan seberapa cepat persediaan barang dagang berhasil dijual kepada pelanggan. Berikut adalah rumus yang digunakan untuk menghitung rasio perputaran persediaan dan lamanya rata-rata perputaran persediaan adalah :

Rasio Perputaran Persediaan

$=\frac{\text { Penjualan }}{\text { Persediaan Awal Tahun }+ \text { Persediaan Akhir Tahun }: 2}$

\section{Hutang}

FASB (Financial Accounting Standard Board) dalam SFAC No.6 mengatakan bahwa Hutang adalah pengorbanan manfaat ekonomi masa mendatang yang timbul karena kewajiban sekarang suatu ekuitas untuk menyerahkan aktiva atau memberikan jasa kepada entitas lain dimasa mendatang sebagai akibat transaksi masa lalu. Menurut Kariyoto (2018 : 195) menyatakan bahwa Hutang ialah kewajiban (Liabilities), maka liabilities ialah hutang yang dipunyai oleh pihak perusahaan yang bersumber Funding Ekstern baik yang berasal dari sumber pinjaman bank, leasing, penerbitan obligasi dan sejenisnya.

\section{Perputaran Hutang}

Prihadi (2013 : 124) Payable turnover (perputaran hutang usaha) digunakan untuk mengukur seberapa sering hutang usaha berputar. Sedangkan menurut Hantono (2018 : 14) Perputaran hutang dagang menunjukan perputaran dagang dalam satu periode tertentu. Ukuran yang terkait yang dapat digunakan untuk mengukur kemampuan sebuah perusahaan membayar sejumlah kewajiban kepada pemasok, dengan menggunakan rasio perputaran hutang usaha (Accounts Payable Turnover), tingkat perputaran hutang usaha merupakan perbandingan antara harga pokok penjualan dengan rata-rata hutang usaha. Rasio perputaran hutang usaha digunakan untuk menunjukan kecepatan yang diperlukan sebuah perusahaan untuk membayar kembali kewajiban lancarnya yang harus dipenuhi kepada pemasok atas pembelian

Copyright (c) 2020 Dyah Ayu Retno Inten, SE., M.Si.

This work is licensed under a Creative Commons Attribution-NonCommercial-ShareAlike 4.0 International License. 
kreditnya Kurniawan, Nugroho, \& Kristanto (2013).

Metode rasio perputaran hutang ini sangat menunjukkan kemampuan perusahaan mebayar hutang akan dipengaruhi oleh tingkat efektivitas perusahaan dalam melakukan pengelolaan hutang-hutangnya tersebut. Rumus untuk menghitung perputaran hutang atau account payable turnover dan menghitung rata-rata perputaran hutang adalah :

Perputaran Hutang $=\frac{\text { Pembelian }}{\text { rata-rata hutang }}$
Rata-rata Hutang $=\frac{\text { Hutang Awal+Hutang Akhir }}{2}$

Dalam menghitung rasio ini harus ditentukan dahulu besarnya pembelian setiap tahunnya, karena jumlah inilah yang dipergunakan sebagai dasar perhitungan Dewi (2015).

\section{Solvabilitas}

Menurut Hantono (2018 : 12) Solvabilitas adalah rasio yang digunakan untuk menghitung leverage perusahaan. Sdangkan menurut Hery (2017: 162) mengemukakan bahwa Rasio solvabilitas merupakan rasio yang digunakan untuk mengukur sejauh mana perusahaan dibiayai oleh hutang. Dan kata lain, rasio solvabilitas merupakan rasio yang digunakan mengukur seberapa besar beban hutang yang di tanggung perusahaan dalam rangka pemenuhan aset.
Menurut Hery (2017 : 163) Rasio solvabilitas memiliki beberapa implikasi sebagai berikut :

1. Kreditor memandang jumlah ekuitas debitor sebagai marjin keamanan (safety margin). Apabila jumlah modal perusahaan debitor kecil maka berarti bahwa kreditor akan menanggung risiko yang besar.

2. Penguasaan atau pengendalian terhadap perusahaan akan tetap berada di tangan debitor atau perusahaan itu sendiri apabila sumber pendanaan berasal dari pinjaman atau hutang.

3. Sumber dana yang berasal dari penerbitan dan penjualan saham akan menimbulkan pengaruh atau bahkan kendali pemegang saham atau investor terhadap perusahaan (investee).Saham menggambarkan kepemilikan investor atas perusahaan investee.

4. Apabila perusahaan memperoleh penghasilan lebih dari dana yang dipinjamnya dibandingkan dengan bunga yang harus dibayarkan kepada kreditor maka kelebihannya tersebut akan memperbesar pengembalian atau imbal hasil (return) bagi pemilik.

\section{Jenis Rasio Solvabilitas}

Menurut Hery (2017 : 166), Jenisjenis rasio solvabilitas yang lazim digunakan dalam praktik untuk mengukur kemampuan perusahaan dalam memenuhi seluruh kewajibanya antara lain, Rasio hutang terhadap asset (Debt to Asset

Copyright (c) 2020 Dyah Ayu Retno Inten, SE., M.Si.

This work is licensed under a Creative Commons Attribution-NonCommercial-ShareAlike 4.0 International License. 
Ratio), Rasio Hutang terhadap Modal (Debt to Equity Ratio), Rasio hutang jangka panjang terhadap Modal (Long Tern Debt to Equity Ratio), Rasio kelipatan Bunga yang Dihasilkan (Times Interest Earned Ratio), dan Rasio Laba Operasional Terhadap Kewajiban (Operating Income to Liabilities Ratio). Pada enelitian ini untuk rasio solvabilitas menggunakan Rasio Hutang terhadap Modal (Debt to Equity Ratio)

Rasio hutang terhadap modal merupakan rasio yang digunakan untuk mengukur besarnya proporsi hutang terhadap modal. Rasio ini dihitung sebagai hasil bagi antara total hutang dengan modal. Rasio ini berguna untuk mengetahui besarnya perbandingan antara jumlah dana yang disediakan oleh kreditor dengan jumlah dana yang berasal dari pemilik perusahaan. Dengan kata lain, rasio ini berfungsi untuk mengetahui berapa bagian dari setiap rupiah modal yang dijadikan sebagai jaminan hutang. Rasio ini memberikan petunjuk umum tentang kelayakan kredit dan risiko keuangan debitor. Berikut adalah rumus yang digunakan untuk menghitung rasio hutang terhadap modal :

$$
\text { Rasio Hutang Terhadap Modal }=\frac{\text { Total Hutang }}{\text { Total Modal }}
$$

\section{Kerangka konseptual}

Gambar1. Kerangka Penelitian

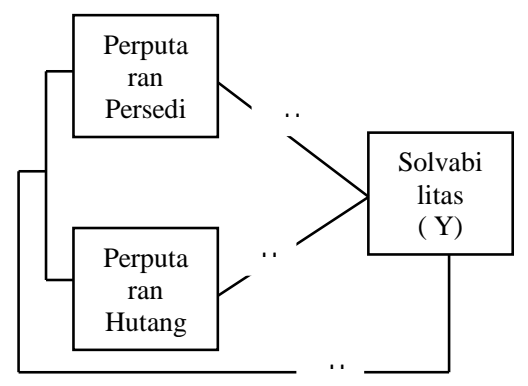

Pengembangan Hipotesis

Berdasarkan landasan teori
dan penelitian terdahulu, dapat
dilihat bahwa
besarnya perputaran persediaan dan
perputaran hutang mempengaruhi
besar kecilnya r solvabilitas
perusahaan. Maka rapat
$\begin{aligned} & \text { dikemukakan hipotesis sebagai } \\ & \text { berikut: }\end{aligned}$ $\mathrm{H} 1$ : perputaran persediaan berpengaruh positif terhadap solvabilitas

H2 : perputaran hutang berpengaruh positif terhadap solvabilitas

H3 : perputaran persediaan dan perputaran hutang berpengaruh terhadap solvabilitas

\section{METODOLOGI PENELITIAN}

Penelitian ini dilakukan di perusahaan manufaktur yang terdaftar di Bursa Efek Indonesia periode 2016-2018. Instrumen penelitian kali ini adalah data sekunder yaitu berupa laporan keuangan tahunan dari perusahaan. Populasi dari penelitian ini adalah seluruh perusahaan manufaktur yang listing di Bursa Efek Indonesia pada

Copyright (c) 2020 Dyah Ayu Retno Inten, SE., M.Si. 
tahun 2016-2018, jumlah populasi yaitu sebanyak 158 perusahaan. Sampel yang diambil sebanyak 89 perusahaan dengan menggunakan purposive sampling

\section{Tabel 1.Teknik Pengumpulan Sampel} Penelitian

\begin{tabular}{|l|l|c|}
\hline NO & \multicolumn{1}{|c|}{ Kriteria } & Jumlah \\
\hline 1 & $\begin{array}{l}\text { Perusahaan yang dipilih } \\
\text { dalam bentuk sektor } \\
\text { manufaktur yang Terdaftar } \\
\text { di Bursa Efek Indonesia } \\
\text { (BEI) untuk periode 2016- } \\
\text { 2018 }\end{array}$ & $\begin{array}{c}158 \\
\text { Perusahaan }\end{array}$ \\
\hline 2 & $\begin{array}{l}\text { Perusahaan selain bank dan } \\
\text { lembaga keuangan }\end{array}$ & $\begin{array}{c}\text { Perusahaan } \\
\text { Perusahaan yang tidak } \\
\text { menerbitkan data laporan } \\
\text { keuangan secara lengkap } \\
\text { selama periode tahun 2016- } \\
\text { 2018 }\end{array}$ \\
\hline 4 & $\begin{array}{l}\text { Mata uang transaksi tidak } \\
\text { menggunakan rupiah }\end{array}$ & $\begin{array}{c}\text { (29) } \\
\text { Perusahaan }\end{array}$ \\
\hline & $\begin{array}{l}\text { Jumlah Sampel Dalam } \\
\text { Penelitian }\end{array}$ & $\begin{array}{l}89 \\
\text { perusahaan }\end{array}$ \\
\hline
\end{tabular}

Tabel 2. Daftar Perusahaan Penelitian

\begin{tabular}{|c|c|c|c|c|c|c|c|}
\hline & \multicolumn{3}{|c|}{ Penelitian } & & & Tbk & \\
\hline \multirow[t]{2}{*}{ No } & \multirow[t]{2}{*}{ Kode } & \multirow[t]{2}{*}{ Nama Perusahaan } & \multirow{2}{*}{$\begin{array}{c}\text { Sektor } \\
\text { Manufakt } \\
\text { ur } \\
\end{array}$} & 32 & SMCB & $\begin{array}{l}\text { Holcim Indonesia } \\
\text { Tbk }\end{array}$ & \\
\hline & & & & \multirow[t]{2}{*}{33} & \multirow[t]{2}{*}{ SMGR } & \multirow{2}{*}{$\begin{array}{l}\text { Semen Indonesia } \\
\text { (Persero }\end{array}$} & \multirow[t]{4}{*}{ Semen } \\
\hline \multirow[t]{2}{*}{1} & \multirow[t]{2}{*}{ ALTO } & \multirow{2}{*}{$\begin{array}{c}\text { Tri Banyan Tirta } \\
\text { Tbk }\end{array}$} & & & & & \\
\hline & & & & \multirow[t]{2}{*}{34} & \multirow[t]{2}{*}{ WTON } & \multirow{2}{*}{$\begin{array}{c}\text { Wijaya Karya } \\
\text { Beton Tbk } \\
\end{array}$} & \\
\hline 2 & DLTA & Delta Djakarta Tbk & & & & & \\
\hline \multirow[t]{2}{*}{3} & \multirow[t]{2}{*}{ ICBP } & \multirow{2}{*}{$\begin{array}{c}\text { Indofood CBP } \\
\text { Sukses Makmur } \\
\text { Tbk } \\
\end{array}$} & & 35 & ALKA & $\begin{array}{c}\text { Alakasa Industrindo } \\
\text { Tbk }\end{array}$ & \multirow{10}{*}{$\begin{array}{l}\text { Logam dan } \\
\text { Sejenisnya }\end{array}$} \\
\hline & & & & \multirow[t]{2}{*}{36} & \multirow[t]{2}{*}{ ALMI } & \multirow{2}{*}{$\begin{array}{c}\text { Alumindo Light } \\
\text { Metal Industry Tbk }\end{array}$} & \\
\hline \multirow[t]{2}{*}{4} & \multirow[t]{2}{*}{ INDF } & \multirow{2}{*}{$\begin{array}{c}\text { Indofood Sukses } \\
\text { Makmur Tbk }\end{array}$} & & & & & \\
\hline & & & & \multirow[t]{2}{*}{37} & \multirow[t]{2}{*}{ BAJA } & \multirow{2}{*}{$\begin{array}{l}\text { Saranacentral } \\
\text { Bajatama Tbk }\end{array}$} & \\
\hline \multirow[t]{2}{*}{5} & \multirow[t]{2}{*}{ MLBI } & \multirow{2}{*}{$\begin{array}{c}\text { Buyung Poetra } \\
\text { Sembada Tbk }\end{array}$} & & & & & \\
\hline & & & & 38 & BTON & Betonjaya & \\
\hline \multirow[t]{2}{*}{6} & \multirow[t]{2}{*}{ ROTI } & \multirow{2}{*}{$\begin{array}{l}\text { Nippon Indosari } \\
\text { Corpindo Tbk }\end{array}$} & \multirow{2}{*}{$\begin{array}{l}\text { Makanan } \\
\text { dan } \\
\text { Minuman }\end{array}$} & & & Manunggal Tbk & \\
\hline & & & & 39 & GDST & $\begin{array}{c}\text { Gunawan Dianjaya } \\
\text { Steel Tbk } \\
\end{array}$ & \\
\hline 7 & SKBM & Sekar Bumi Tbk & & 40 & INAI & Indal Aluminium & \\
\hline 8 & SKLT & Sekar Lbkaut T & & & & Industry Tbk & \\
\hline
\end{tabular}

\begin{tabular}{|c|c|c|c|}
\hline 9 & STTP & Siantar Top Tbk & \\
\hline 10 & ULTJ & $\begin{array}{l}\text { Ultra Jaya Milk } \\
\text { Industry Tbk }\end{array}$ & \\
\hline 11 & MYOR & Mayora Indah Tbk & $\begin{array}{l}\text { Makanan } \\
\text { dan } \\
\text { minuman }\end{array}$ \\
\hline 12 & DVLA & $\begin{array}{c}\text { Darya Varia } \\
\text { Laboratoria Tbk }\end{array}$ & \multirow[b]{4}{*}{ Farmasi } \\
\hline 13 & KAEF & Kimia Farma Tbk & \\
\hline 14 & KLBF & Kalbe Farma Tbk & \\
\hline 15 & MERK & Merek Indonesia & \\
\hline
\end{tabular}

\begin{tabular}{|c|c|c|c|}
\hline & & Tbk & \\
\hline 16 & PYFA & $\begin{array}{c}\text { Pyridam Farma } \\
\text { Tbk } \\
\end{array}$ & \\
\hline 17 & TSPC & $\begin{array}{l}\text { Tempo Sean } \\
\text { Pacific Tbk }\end{array}$ & \\
\hline 18 & ADES & $\begin{array}{c}\text { Akasha Wira } \\
\text { International Tbk }\end{array}$ & \multirow{5}{*}{$\begin{array}{c}\text { Kosmetik } \\
\text { dan Barang } \\
\text { Keperluan } \\
\text { Rumah } \\
\text { Tangga }\end{array}$} \\
\hline 19 & MBTO & Martina Berto Tbk & \\
\hline 20 & MRAT & Mustika Ratu Tbk & \\
\hline 21 & TCID & $\begin{array}{c}\text { Mandom Indonesia } \\
\text { Tbk }\end{array}$ & \\
\hline 22 & UNVR & $\begin{array}{l}\text { Unilever Indonesia } \\
\text { Tbk }\end{array}$ & \\
\hline 23 & GGRM & $\begin{array}{c}\text { Gudang Garam } \\
\text { Tbk }\end{array}$ & \multirow{4}{*}{ Rokok } \\
\hline 24 & HMSP & $\begin{array}{l}\text { Hanjaya Mandala } \\
\text { Sampoerna Tbk }\end{array}$ & \\
\hline 25 & RMBA & $\begin{array}{c}\text { Bentoel } \\
\text { International } \\
\text { Investama Tbk }\end{array}$ & \\
\hline 26 & WIIM & $\begin{array}{l}\text { Wismilak Inti } \\
\text { Makmur Tbk }\end{array}$ & \\
\hline 27 & CINT & $\begin{array}{c}\text { Chitose } \\
\text { International Tbk }\end{array}$ & \multirow{3}{*}{$\begin{array}{l}\text { Peralatan } \\
\text { Rumah } \\
\text { Tangga } \\
\end{array}$} \\
\hline 28 & KICI & $\begin{array}{c}\text { Kedaung Indah } \\
\text { Can Tbk }\end{array}$ & \\
\hline 29 & LMPI & $\begin{array}{l}\text { Langgeng Makmur } \\
\text { Industri Tbk }\end{array}$ & \\
\hline 30 & INTP & $\begin{array}{c}\text { Indocement } \\
\text { Tunggal Prakasa } \\
\text { Tbk }\end{array}$ & \multirow{3}{*}{ Semen } \\
\hline 31 & SMBR & $\begin{array}{c}\text { Semen Baturaja } \\
\text { Tbk }\end{array}$ & \\
\hline 32 & SMCB & $\begin{array}{l}\text { Holcim Indonesia } \\
\text { Tbk }\end{array}$ & \\
\hline 33 & SMGR & $\begin{array}{l}\text { Semen Indonesia } \\
\text { (Persero }\end{array}$ & \multirow[t]{2}{*}{ Semen } \\
\hline 34 & WTON & $\begin{array}{c}\text { Wijaya Karya } \\
\text { Beton Tbk }\end{array}$ & \\
\hline 35 & ALKA & $\begin{array}{c}\text { Alakasa Industrindo } \\
\text { Tbk }\end{array}$ & \multirow{6}{*}{$\begin{array}{l}\text { Logam dan } \\
\text { Sejenisnya }\end{array}$} \\
\hline 36 & ALMI & $\begin{array}{c}\text { Alumindo Light } \\
\text { Metal Industry Tbk }\end{array}$ & \\
\hline 37 & BAJA & $\begin{array}{l}\text { Saranacentral } \\
\text { Bajatama Tbk }\end{array}$ & \\
\hline 38 & BTON & $\begin{array}{c}\text { Betonjaya } \\
\text { Manunggal Tbk }\end{array}$ & \\
\hline 39 & GDST & $\begin{array}{c}\text { Gunawan Dianjaya } \\
\text { Steel Tbk } \\
\end{array}$ & \\
\hline 40 & INAI & $\begin{array}{l}\text { Indal Aluminium } \\
\text { Industry Tbk }\end{array}$ & \\
\hline
\end{tabular}

Copyright (c) 2020 Dyah Ayu Retno Inten, SE., M.Si.

\begin{tabular}{|c|c|c|}
\hline 41 & JKSW & $\begin{array}{c}\text { Jakarta Kyoei Steel } \\
\text { Works Tbk }\end{array}$ \\
\hline 42 & JPRS & Jaya Pari Steel Tbk \\
\hline 43 & LMSH & $\begin{array}{c}\text { Lionmesh Prima } \\
\text { Tbk }\end{array}$ \\
\hline 44 & AMFG & $\begin{array}{c}\text { Asahimas Flat } \\
\text { Glass Tbk }\end{array}$ \\
\hline 45 & ARNA & Arwana Citramulia \\
\hline
\end{tabular}

This work is licensed under a Creative Commons Attribution-NonCommercial-ShareAlike 4.0 International License. 


\begin{tabular}{|c|c|c|c|}
\hline & & Tbk & \multirow{4}{*}{$\begin{array}{l}\text { Keramik } \\
\text { Porselen }\end{array}$} \\
\hline 46 & IKAI & $\begin{array}{c}\text { Intikeramik } \\
\text { Alamasri Industri } \\
\text { Tbk } \\
\end{array}$ & \\
\hline 47 & KIAS & $\begin{array}{c}\text { Keramika Indonesia } \\
\text { Assosiasi Tbk }\end{array}$ & \\
\hline 48 & TOTO & $\begin{array}{c}\text { Surya Toto } \\
\text { Indonesia Tbk } \\
\end{array}$ & \\
\hline 49 & BUDI & Budi Acid Jaya Tbk & \multirow{4}{*}{ Kimia } \\
\hline 50 & DPNS & $\begin{array}{c}\text { Duta Pertiwi } \\
\text { Nusantara Tbk } \\
\end{array}$ & \\
\hline 51 & EKAD & $\begin{array}{c}\text { Ekadharma } \\
\text { International Tbk }\end{array}$ & \\
\hline 52 & SRSN & $\begin{array}{c}\text { Indo Acidatama } \\
\text { Tbk } \\
\end{array}$ & \\
\hline 53 & AKPI & $\begin{array}{l}\text { Argha Karya Prima } \\
\text { Industries Tbk }\end{array}$ & \multirow{2}{*}{$\begin{array}{l}\text { Plastik dan } \\
\text { Kemasan }\end{array}$} \\
\hline 54 & APLI & $\begin{array}{c}\text { Asiaplast Industries } \\
\text { Tbk } \\
\end{array}$ & \\
\hline 55 & BRNA & Berlina Tbk & \multirow{7}{*}{$\begin{array}{l}\text { Plastik dan } \\
\text { Kemasan }\end{array}$} \\
\hline 56 & IGAR & $\begin{array}{l}\text { Champion Pacific } \\
\text { Indonesia Tbk }\end{array}$ & \\
\hline 57 & IMPC & $\begin{array}{c}\text { Impack Pratama } \\
\text { Industri Tbk }\end{array}$ & \\
\hline 58 & SIAP & $\begin{array}{c}\text { Sekawan } \\
\text { Intipratama Tbk }\end{array}$ & \\
\hline 59 & TALF & Tunas Alfin Tbk & \\
\hline 60 & TRST & Trias Sentosa Tbk & \\
\hline 61 & YPAS & $\begin{array}{c}\text { Yanaprima } \\
\text { Hastapersada Tbk }\end{array}$ & \\
\hline 62 & CPIN & $\begin{array}{l}\text { Charoen Pokphand } \\
\text { Indonesia Tbk }\end{array}$ & \multirow{4}{*}{$\begin{array}{l}\text { Pakan } \\
\text { Ternak }\end{array}$} \\
\hline 63 & JPFA & $\begin{array}{l}\text { Japfa Comfeed } \\
\text { Indonesia Tbk }\end{array}$ & \\
\hline 64 & MAIN & $\begin{array}{c}\text { Malindo Feedmill } \\
\text { Tbk } \\
\end{array}$ & \\
\hline 65 & SIPD & Sierad Produce Tbk & \\
\hline 66 & TIRT & $\begin{array}{l}\text { Tirta Mahakam } \\
\text { Resources Tbk }\end{array}$ & $\begin{array}{c}\text { Kayu dan } \\
\text { Pengelolah } \\
\text { anya } \\
\end{array}$ \\
\hline 67 & ALDO & $\begin{array}{c}\text { Alkindo Naratama } \\
\text { Tbk } \\
\end{array}$ & \multirow{5}{*}{ Pulpen dan } \\
\hline 68 & FASW & $\begin{array}{c}\text { Fajar Surya Wisesa } \\
\text { Tbk }\end{array}$ & \\
\hline 69 & KBRI & $\begin{array}{c}\text { Kertas Basuki } \\
\text { Rachmat Indonesia } \\
\text { Tbk } \\
\end{array}$ & \\
\hline 70 & KDSI & $\begin{array}{c}\text { Kedawung Setia } \\
\text { Industrial Tbk }\end{array}$ & \\
\hline 71 & SPMA & Suparma Tbk & \\
\hline 72 & ASII & $\begin{array}{c}\text { Astra International } \\
\text { Tbk } \\
\end{array}$ & \multirow{3}{*}{$\begin{array}{l}\text { Otomotif } \\
\text { Dan } \\
\text { komponen }\end{array}$} \\
\hline 73 & AUTO & Astra Otoparts Tbk & \\
\hline 74 & GJTL & Gajah Tunggal Tbk & \\
\hline 75 & IMAS & $\begin{array}{l}\text { Indomobil Sukses } \\
\text { Internasional Tbk }\end{array}$ & \\
\hline 76 & INDS & Indospring Tbk & \multirow{2}{*}{$\begin{array}{l}\text { otomotif } \\
\text { Dan } \\
\text { Komponen }\end{array}$} \\
\hline 77 & NIPS & Nipress Tbk & \\
\hline
\end{tabular}

\begin{tabular}{|c|c|c|c|}
\hline 78 & SMSM & $\begin{array}{c}\text { Selamat Sempurna } \\
\text { Tbk }\end{array}$ & \\
\hline 79 & HDTX & $\begin{array}{c}\text { Panasia Indo } \\
\text { Resources Tbk } \\
\end{array}$ & $\begin{array}{c}\text { Tekstil dan } \\
\text { Garment }\end{array}$ \\
\hline 80 & MYTX & $\begin{array}{c}\text { Asia Pacific } \\
\text { Investama Tbk }\end{array}$ & \multirow{5}{*}{$\begin{array}{c}\text { Tekstil dan } \\
\text { Garment }\end{array}$} \\
\hline 81 & SSTM & $\begin{array}{c}\text { Sunson Textile } \\
\text { Manufacture Tbk }\end{array}$ & \\
\hline 82 & STAR & Star Petrochem Tbk & \\
\hline 83 & TRIS & $\begin{array}{l}\text { Trisula International } \\
\text { Tbk }\end{array}$ & \\
\hline 84 & UNIT & $\begin{array}{c}\text { Nusantara Inti } \\
\text { Corpora Tbk }\end{array}$ & \\
\hline 85 & BIMA & $\begin{array}{l}\text { Primarindo Asia } \\
\text { Infrastructure Tbk }\end{array}$ & \multirow[t]{2}{*}{ Alas Kaki } \\
\hline 86 & JECC & $\begin{array}{c}\text { Jembo Cable } \\
\text { Company Tbk }\end{array}$ & \\
\hline 87 & KBLI & $\begin{array}{c}\text { KMI Wire \& Cable } \\
\text { Tbk }\end{array}$ & \multirow{3}{*}{ Kabel } \\
\hline 88 & SCCO & $\begin{array}{l}\text { Supreme Cable } \\
\text { Manufacturing }\end{array}$ & \\
\hline 89 & VOKS & Voksel Electric Tbk & \\
\hline
\end{tabular}

\section{HASIL PENELITIAN DAN PEMBAHASAN}

\section{Statistik Deskriptif}

Statistik deskriptif memberikan suatu gambaran atau deskripsi data melalui penjabaran nilai minimum, maksimum, rata-rata (mean), dan standar deviasi dari setiap variabel penelitian. Hasil pengujian statistik deskriptif dapat dilihat pada tabel 3 sebagai berikut :

Tabel 3

Statistik Deskriptif Descriptive Statistics

\begin{tabular}{|c|c|c|c|c|c|}
\hline & $\mathrm{N}$ & $\begin{array}{c}\text { Minim } \\
\text { um }\end{array}$ & $\begin{array}{c}\text { Maxim } \\
\text { um }\end{array}$ & Mean & $\begin{array}{c}\text { Std. } \\
\text { Deviatio } \\
\text { n }\end{array}$ \\
\hline $\begin{array}{l}\text { DER } \\
\text { APT }\end{array}$ & 267 & $\begin{array}{r}-225.00 \\
.00\end{array}$ & $\begin{array}{r}1766.9 \\
1 \\
14.60\end{array}$ & $\begin{array}{l}8.8728 \\
2.0477\end{array}$ & $\begin{array}{r}114.079 \\
32 \\
1.76423\end{array}$ \\
\hline $\begin{array}{l}\text { ITO } \\
\text { Valid N } \\
\text { (listwis } \\
\text { e) }\end{array}$ & $\begin{array}{l}267 \\
267\end{array}$ & .32 & 61.35 & 5.6042 & 6.24571 \\
\hline
\end{tabular}

Copyright (c) 2020 Dyah Ayu Retno Inten, SE., M.Si.

This work is licensed under a Creative Commons Attribution-NonCommercial-ShareAlike 4.0 International License. 
Setelah dilakukan pengolahan data, dapat dilihat bahwa terdapat perubahan jumlah sampel. Tabel 3 menunjukkan bahwa jumlah data yang valid pada penelitian ini adalah sebanyak 267 sampel. Dari 267 sampel data DER, nilai minimum sebesar -225,00, dengan nilai maksimum 17666,91. Nilai rata-rata sebesar 8,8728 dengan standar deviasi 114,07932. Dari 267 data APT, nilai minimum sebesar 0,00 , dengan nilai maksimum 14,60. Niai rata-rata sebesar 2,0477 dan nilai standar deviasi sebesar 1,76423. Data yang valid dari variabel Inventory Turn over adalah sebesar 267 dengan nilai minimum 0,32 , dengan nilai maksimum 61,35. Nilai rata-rata sebesar 5,6042 dengan standar deviasi sebesar 6,24571.

\section{Uji Normalitas}

Tabel 4

Hasil Uji Statistik Kolmogorov-Smirnov One-Sample Kolmogorov-Smirnov Test

\begin{tabular}{|ll|r|}
\hline & & \multicolumn{1}{|c|}{$\begin{array}{c}\text { Unstandardized } \\
\text { Residual }\end{array}$} \\
\hline $\mathrm{N}$ & Mean & 267 \\
Normal & Std. & .0000000 \\
Parameters & Deviation & \\
& Absolute & .448 \\
Most Extreme & Positive & .448 \\
Differences & Negative & -.426 \\
Kolmogorov-Smirnov Z & 7.327 \\
Asymp. Sig. (2-tailed) & .000 \\
\hline a. Test distribution is Normal. \\
b. Calculated from data.
\end{tabular}

Dari tabel 4 diatas menunjukan bahwa tingkat signifikan adalah 0,000 yang berada dibawah 0,05 , sehingga tabel dari hasil tabel tersebut dapat disimpulkan bahwa data tidak terdistribusi secara normal.

\section{Uji Multikolenieritas}

Tabel 5. Hasil Uji Multikolonieritas Coefficients $^{\mathrm{a}}$

\begin{tabular}{|c|c|c|c|}
\hline \multirow[b]{2}{*}{ Mod } & & \multicolumn{2}{|c|}{ Collinearity Statistics } \\
\hline & & Tolerance & VIF \\
\hline 1 & ITO & .884 & 1.131 \\
\hline & APT & .884 & 1.131 \\
\hline
\end{tabular}

hasil perhitungan nilai tolerance menunjukkan bahwa tidak ada variabel independen yang memiliki nilai toleransi $<0,10$ dan nilai VIF $>$ 10. menunjukkan nilai tolerance Perputaran Persediaan dan Perputaran Hutang sebesar 0,884 > tingkat kesalahan sebesar 0,10 . Kemudian nilai VIF Perputaran Persediaan dan Perputaran Hutang sebesar 1,131 < penyimpangan baku sebesar 10. Jadi dapat disimpulkan bahwa Perputaran Persediaan dan Perputaran Hutang tidak terjadi multikolonieritas antar variabel independen.

\section{Uji Autokorelasi}

Tabel 6. Uji Autokorelasi Menggunakan Runt Test Runs Test

\begin{tabular}{|l|r|}
\hline & Unstandardized Residual \\
\hline Test Value $^{\mathrm{a}}$ & -.01312 \\
Cases < Test Value & 127 \\
Cases >= Test Value & 128 \\
Total Cases & 255 \\
Number of Runs & 115 \\
Z & -1.694 \\
Asymp. Sig. (2-tailed) & .090 \\
\hline
\end{tabular}

Copyright (c) 2020 Dyah Ayu Retno Inten, SE., M.Si.

This work is licensed under a Creative Commons Attribution-NonCommercial-ShareAlike 4.0 International License. 
a. Median

Hasil pengujian menunjukan bahwa nilai test adalah -0,01312, dengan nilai Asymp. Sig. (2-tailed), adalah sebesar 0,090. Batas nilai Asymp. Sig. untuk terbebas dari autokorelasi adalah sebesar 0,05. Yang berarti hipotesis nol diterima, sehingga dapat disimpulkan bahwa residual random, atau tidak terjadi autokorelasi.

\section{Uji Heterokedastisitas}

\section{Gambar 2. Hasil Uji Heteroskedastisitas}

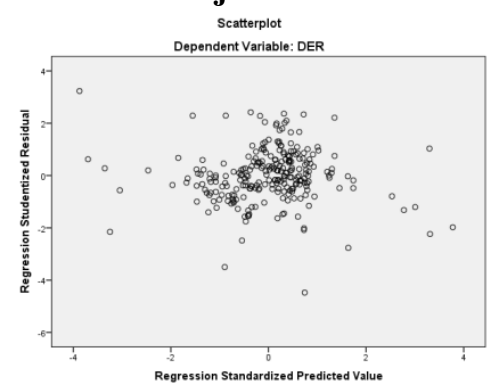

Dari grafik scatterplot terlihat bahwa titik-titik menyebar secara acak serta tersebar secara baik di atas maupun di bawah angka 0 pada sumbu $\mathrm{Y}$ dan disisi kiri maupun disisi kanan angka 0 pada sumbu $X$. Sehingga dapat disimpulkan bahwa tidak terjadi heteroskedastisitas pada model regresi.

\section{Analisis Regresi}

Tabel 9. Hasil Uji Regresi Berganda

\begin{tabular}{|l|r|c|c|c|c|}
\hline Model & \multicolumn{2}{|c|}{ Coefficients $^{\mathrm{a}}$} \\
& $\begin{array}{c}\text { Unstandardi } \\
\text { zed } \\
\text { Coefficients }\end{array}$ & $\begin{array}{c}\text { Standardi } \\
\text { zed } \\
\text { Coefficien } \\
\text { ts }\end{array}$ & t & Sig \\
\cline { 2 - 4 } & B & $\begin{array}{c}\text { Std. } \\
\text { Error }\end{array}$ & Beta & & \\
\hline 1 (Consta \\
nt)
\end{tabular}

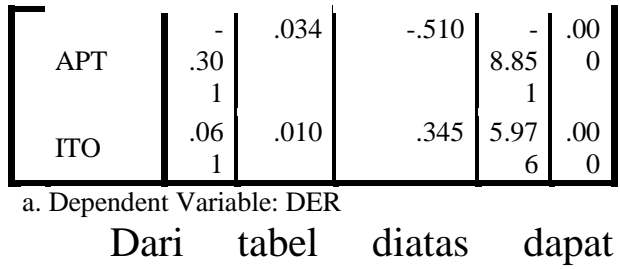
disusun persamaan regresi sebagai berikut:

$\mathrm{Y}=\mathbf{0 , 0 1 5}+\mathrm{X} 1 \mathrm{0,061}-\mathbf{0 , 3 0 1} \mathrm{X} 2+\mathrm{e}$ Dari tampilan output SPSS unstandardized beta coefficients dapat dibangun sebuah persamaan matematis sebagai berikut :

DER $=0,015+0,061$ Perputaran Persediaan - 0,301 Perputaran Hutang $+0,05$

1. Konstanta sebesar 0,015 menyatakan bahwa jika Perputaran Persediaan dan Perputaran Hutang dianggap konstan, maka Debt to Equity Ratio nilainya sebesar 0,015 .

2. Koefisien regresi Perputaran Persediaan sebesar 0,061, menyatakan bahwa setiap kenaikan Perputaran Persediaan sebesar 1 satuan akan meningkatkan Debt to Equity Ratio sebesar 0,061.

3. Koefisien regresi Perputaran Hutang sebesar -0,301 , menyatakan bahwa setiap kenaikan Perputaran Hutang sebesar 1 satuan akan menurunkan Debt to Equity Ratio sebesar -0,301.

4. 0,05 menyatakan bahwa tingkat kesalahan Perputaran Persediaan dan Perputaran Hutang terhadap Debt to Equity Ratio sebesar 0,05 atau $5 \%$.

Copyright (c) 2020 Dyah Ayu Retno Inten, SE., M.Si. 


\section{Uji Statistik T (Uji t)}

Tabel 10. Hasil Uji Statistik t Parsial

\begin{tabular}{|c|c|c|c|c|c|}
\hline \multirow[b]{2}{*}{ Model } & \multicolumn{2}{|c|}{$\begin{array}{l}\text { Unstandardize } \\
\text { d Coefficients }\end{array}$} & \multirow{2}{*}{$\begin{array}{c}\begin{array}{c}\text { Standardize } \\
\mathrm{d} \\
\text { Coefficients }\end{array} \\
\text { Beta }\end{array}$} & \multirow[b]{2}{*}{$\mathrm{t}$} & \multirow[b]{2}{*}{ Sig. } \\
\hline & B & $\begin{array}{l}\text { Std. } \\
\text { Error }\end{array}$ & & & \\
\hline 1 (Constant & .457 & .087 & & $\begin{array}{r}5.23 \\
0\end{array}$ & $\begin{array}{r}.00 \\
0\end{array}$ \\
\hline ITO & .030 & .011 & .171 & $\begin{array}{r}2.75 \\
9\end{array}$ & $\begin{array}{r}.00 \\
0\end{array}$ \\
\hline
\end{tabular}

Perputaran Persediaan dengan $t_{\text {hitung }}$ sebesar 2,759 $>t_{\text {tabel }}$ sebesar 1,9693 dan tingkat signifikansi 0,000 $<$ tingkat kesalahan sebesar 0,05. Maka Ha diterima atau Perputaran Hutang terdapat pengaruh terhadap Debt to Equity Ratio.

Tabel 11. Hasil Uji Statistik t Parsial Coefficients $^{\mathrm{a}}$

\begin{tabular}{|c|c|c|c|c|c|}
\hline \multirow[b]{2}{*}{ Model } & \multicolumn{2}{|c|}{$\begin{array}{l}\text { Unstandardize } \\
\text { d Coefficients }\end{array}$} & \multirow{2}{*}{$\begin{array}{c}\begin{array}{c}\text { Standardize } \\
\mathrm{d} \\
\text { Coefficients }\end{array} \\
\text { Beta }\end{array}$} & \multirow[b]{2}{*}{$\mathrm{t}$} & \multirow[b]{2}{*}{ Sig. } \\
\hline & B & $\begin{array}{l}\text { Std. } \\
\text { Error }\end{array}$ & & & \\
\hline 1 (Constant & 197 & .094 & & $\begin{array}{r}2.09 \\
5\end{array}$ & $\begin{array}{r}.03 \\
7\end{array}$ \\
\hline APT & .232 & .034 & -.393 & $\begin{array}{r}6.79 \\
9\end{array}$ & $\begin{array}{r}.00 \\
0\end{array}$ \\
\hline
\end{tabular}

Perputaran Hutang dengan $t_{\text {hitung }}$ sebesar $-6.799<t_{\text {tabel }}$ sebesar 1,9693 dan tingkat signifikansi 0,000 $<$ tingkat kesalahan sebesar 0,05. Maka Ha diterima atau Perputaran Persediaan terdapat pengaruh terhadap Debt to Equity Ratio.

Tabel 12. Hasil Uji Statistik t

$$
\text { Coefficients }^{\mathrm{a}}
$$

\begin{tabular}{|c|c|c|c|c|c|}
\hline \multirow[t]{2}{*}{ Model } & \multicolumn{2}{|c|}{$\begin{array}{l}\text { Unstandardi } \\
\text { zed } \\
\text { Coefficients }\end{array}$} & $\begin{array}{c}\text { Standardi } \\
\text { zed } \\
\text { Coefficien } \\
\text { ts }\end{array}$ & $\mathrm{t}$ & Sig \\
\hline & B & $\begin{array}{l}\text { Std. } \\
\text { Error }\end{array}$ & Beta & & \\
\hline $\begin{array}{l}\text { (Consta } \\
\mathrm{nt})\end{array}$ & $\begin{array}{r}.01 \\
5\end{array}$ & .093 & & .157 & \\
\hline 1 APT & $\begin{array}{r}- \\
.30 \\
1\end{array}$ & .034 & -.510 & $\begin{array}{r}- \\
8.85 \\
1\end{array}$ & $\begin{array}{r}.00 \\
0\end{array}$ \\
\hline ITO & $\begin{array}{r}.06 \\
1\end{array}$ & .010 & .345 & $\begin{array}{r}5.97 \\
6\end{array}$ & $\begin{array}{r}.00 \\
0\end{array}$ \\
\hline
\end{tabular}

Uji signifikansi dapat dilihat pada nilai $t$ dan nilai signifikansi dari masing-masing variabel yang ada pada tabel 12, antara lain :

1. Perputaran Persediaan dengan $t_{\text {hitung }}$ sebesar $5,976>t_{\text {tabel }}$ sebesar 1,9693 dan tingkat signifikansi $0,000<$ tingkat kesalahan sebesar 0,05. Maka Ha diterima atau Perputaran Persediaan terdapat pengaruh terhadap Debt to Equity Ratio.

2. Perputaran Hutang dengan $t_{\text {hitung }}$ sebesar $-8,851<\mathrm{t}_{\text {tabel }}$ sebesar 1,9693 dan tingkat signifikansi $0,000<$ tingkat kesalahan sebesar 0,05. Maka Ha diterima atau Perputaran Hutang terdapat pengaruh terhadap Debt to Equity Ratio.

\section{Uji Koefisien Determinasi $\left(\mathbf{R}^{2}\right)$}

Tabel 13. Hasil Uji Koefisien Determinasi Model Summary ${ }^{\mathrm{b}}$

\begin{tabular}{|l|c|r|r|r|}
\hline Model & $\mathrm{R}$ & $\begin{array}{c}\mathrm{R} \\
\text { Square }\end{array}$ & $\begin{array}{c}\text { Adjusted R } \\
\text { Square }\end{array}$ & $\begin{array}{c}\text { Std. Error of } \\
\text { the Estimate }\end{array}$ \\
\hline 1 & $.509^{\mathrm{a}}$ & .259 & .254 & .90086 \\
\hline
\end{tabular}
a. Predictors: (Constant), ITO, APT

b. Dependent Variable: DER

Berdasarkan hasil uji koefisien determinasi pada tabel 13 diatas, besarnya nilai adjusted $\mathrm{R}^{2}$ dalam model regresi perusahaan

Copyright (c) 2020 Dyah Ayu Retno Inten, SE., M.Si.

\section{cc) (†)}

This work is licensed under a Creative Commons Attribution-NonCommercial-ShareAlike 4.0 International License. 
manufaktur diperoleh sebesar 0,254. Hal ini menunjukan bahwa besar pengaruh variabel independen yaitu perputaran persediaan, perputaran hutang terhadap variabel dependen DER yang dapat diterangkan oleh persamaan ini sebesar $25,4 \%$. Sedangkan sisanya sebesar $74,6 \%$ dipengaruhi oleh faktor lain yang tidak dimasukan dalam model regresi. Selain itu dapat dilihat nilai $\mathrm{R}^{2}$ nya sebesar 0,259 . Jika nilai $\mathrm{R}^{2}$ mendekati 1 maka variabel bebas semakin kuat pengaruhnya terhadap variabel dependen.

\section{KESIMPULAN DAN SARAN}

\section{Kesimpulan}

1. Pengaruh perputaran persediaan terhadap solvabilitas memiliki tanda positif. Artinya, apabila terjadi peningkatan perputaran persediaan, dengan anggapan variabel yang lain konstan, maka akan diikuti dengan kenaikan profitabilitas. Uji hipotesis menyatakan bahwa perputaran persediaan berpengaruh positif terhadap Solvabilitas (DER). Adanya pengaruh positif antara perputaran persediaan dengan solvabilitas terjadi karena kemampuan perusahaan dalam membayar hutang dipengaruhi oleh tingkat efektivitas perusahaan dalam pengelolaan persediaan. Pengelolaan persediaan merupakan bagian penting untuk kemajuan perusahaan dalam mengendalikan persediaanya. Pengukuran perputaran persediaan merupakan salah satu bentuk perusahan dalam mengendalikan persediaanya dalam meningkatkan efektivitas pengelolaanya, dan juga karena semakin pendeknya waktu yang dibutuhkan perusahaan untuk menghabiskan persediaan, maka semakin kecil biaya yang harus dikeluarkan oleh perusahaan untuk biaya pemeliharaan. Semakin rendahnya biaya yang harus dikeluarkan, maka laba perusahaan akan semakin naik.

2. Perputaran hutang terdapat pengaruh negatif terhadap Debt to Equity Ratio. Efektivitas Pengelolaan utang bagi perusahaan dilakukan dengan tujuan agar dalam jangka panjang dapat dicapai biaya utang yang minimal dengan tingkat risiko yang terkendali, dan mampu digunakan sebagai pengukuran kinerja, strategi yang ditetapkan oleh perusahaan mengarah pada tujuan pengelolaan utang yang dapat menjamin terpenuhnya kebutuhan pembiayaan secara efisien dan mendukung kesinambungan keuangan perusahaan, menjaga agar pengelolaan dilakukan scara efektif. Kemampuan perusahaan dalam mebayar hutang akan dipengaruhi oleh tingkat efektivitas perusahaan dalam pengelolaan hutangnya. Pengukuran perputaran hutang merupakan salah satu bentuk perusahan dalam mengendalikan hutang. Perputaran Hutang

Copyright (c) 2020 Dyah Ayu Retno Inten, SE., M.Si.

This work is licensed under a Creative Commons Attribution-NonCommercial-ShareAlike 4.0 International License. 
(APT) yaitu rasio yang digunakan untuk mengukur seberapa sering utang usaha berputar, perputaran hutang merupakan ukuran terkait yang dapat digunakan untuk kemampuan sebuah perusahaan membayar sejumlah kewajiban kepada pemasok. Perputaran hutang yang tinggi menandakan kondisi keuangan perusahaan yang baik, maka hal tersebut menandakan bahwa perusahaan membayar pemasok lebih cepat, dalam situasi seperti ini perusahaan mampu memenuhi kewajibanya dalam melunasi hutang-hutangnya, hal ini menandakan adanya keharusan suatu perusahaan untuk menghasilkan laba yang tinggi agar seluruh kewajiban dapat dibayarkan. Sebaliknya, jika tingkat perputaran hutang perusahaan rendah maka hal tersebut mengindikasikan bahwa perusahaan membutuhkan waktu lebih lama unuk membayar pemasoknya.

\section{Saran}

Setelah mengkaji hasil penelitian ini maka implikasi manajerial yang dapat penulis ajukan adalah sebagai berikut :

1. Agar dapat meningkatkan keuntungan, perusahaan manufaktur harus memperhatikan jumlah persediaan yang terlalu besar dibanding dengan kebutuhan, kesalahan dalam menentukan jumlah persediaan dapat menyebabkan perusahaan kehilangan kesempatan untuk meraih keuntungan. Jumlah persediaan yang terlalu besar dibanding dengan kebutuhan, akan menyebabkan beban yang harus ditanggung perusahaan menjadi besar seperti, biaya penyimpanan, pemeliharaan gudang, resiko kerusakan, menurunnya kualitas barang dalam penyimpanan, semua itu adalah faktor yang menyebabkan keuntungan perusahaan berkurang, sebaliknya jika persediaan yang terlalu kecil dapat menghambat operasional perusahaan berupa tidak tersediaanya barang pada saat dibutuhkan sehingga menyebabkan perusahaan kehilangan kesempatan untuk meraih laba

2. Temuan pada penelitian ini menyebutkan bahwa perputaran hutang berpengaruh negatif signifikan terhadap DER. Adanya pengaruh negatif ini. Dimungkinkan karena perusahaan mendapatkan syarat kredit yang kurang menguntungkan. Sehingga perusahaan tidak dapat mengalokasikan dananya secara maksimal. Agar dapat meningkatkan DER perusahaan sebaiknya meminta persyaratan kredit baru kepada supplier, karena perputaran hutang yang ada. Menimbulkan efek yang berbanding balik dengan solvabilitasnya. perushaan akan mengalami kerugian

Copyright (c) 2020 Dyah Ayu Retno Inten, SE., M.Si.

This work is licensed under a Creative Commons Attribution-NonCommercial-ShareAlike 4.0 International License. 
akibat berbagai jenis masalah yang terkait dengan pembayaran yang terlambat dan biaya-biaya tambahan hutang

3. Untuk penelitian selanjutnya disarankan tidak hanya menggunakan perusahaan sektor manufaktur sebagai sampel penelitian, tetapi juga disarankan menggunakan perusahaan sektor lain yang terdaftar di Bursa Efek Indonesia (BEI) seperti perusahaan sektor pertambangan, perusahaan sektor perbankan, perusahaan sektor transportasi, perusahaan sektor tekomunikasi, perusahaan sektor asuransi dan perusahaan dari sektor lainnya. Untuk penelitian selanjutnya disarankan agar menambah sampel tahun pengamatan karena dengan pengamatan yang lebih lama mungkin akan meningkatkan hasil yang lebih baik dan menambah lebih banyak variabel lain yang dapat mempengaruhi pengungkapan tanggung jawab sosial perusahaan agar mendapat hasil yang lebih baik.

\section{DAFTAR PUSTAKA}

Abdulllah, I. (2015). Untuk Menilai Kinerja Keuangan Pada Pt . Aneka Gas Industri, 182-190.

Andika, M. D. (2018). Panduan Merencanakan, Mengawasi, dan Mengeksekusi Bisnis. Yogyakarta.
Anggraini. (2017). Analisis efisiensi biaya dengan menggunakan metode lot for lot dalam pengendalian persediaan. Analisis Efisiensi Biaya Dengan Menggunakan Metode LOT FOR LOT Dalam Pengendalian Persediaan, 142-152.

Anwar, F., \& Karamoy, H. (2014). Analisis Penerapan Metode Pencatatan Dan Penilaian Terhadap Persediaan Barang Menurut Psak No.14 Pada Pt. Tirta Investama Dc Manado. Jurnal EMBA, Volume 2(2), 1296-1305.

Bash, E. (2015). 5-2) No Title No Title. PhD Proposal, 1(April), $1-4$.

https://doi.org/10.1017/CBO978 1107415324.004

Dewi, H. P. (2015). Pengaruh Perputaran Piutang Dan Hutang Terhadap Arus Kas Operasi. Studi Pada Pt Exer Indonesia, Vol. 2, 14-24.

Hantono. (2018). Konsep Analisa Laporan Keuangan dengan Pedekatan Rasio dan SPSS. Yogyakarta.

Hargiansyah, R. F., Rahayu, M. N. S. S. R. H. S. M., Martikarini, N., Wahyudi, H. D., Chuzaimah, Sugiarti, D., ... Muid, A. (2014). Pengaruh Ukuran Perusahaan , Leverage dan Profitabilitas terhadap Nilai Perusahaan ( Studi Empiris pada Perusahaan Manufaktur yang Terdaftar di Bursa Efek

Copyright (c) 2020 Dyah Ayu Retno Inten, SE., M.Si. 
Indonesia ). Jurnal Administrasi Bisnis, 2(1), 1-10. https://doi.org/10.1017/CBO978 1107415324.004

Haryanti, C. S. (2014). Analisis Perbandingan Laporan Keuangan Untuk Menilai Kinerja Keuangan Pada Perusahaan Telekomunikasi ( Studi Kasus BEI ), 1(1), 52-86.

Hery, S.E., M.Si., RSA., C. (2016). Mengenal Dan Memahami Dasar-Dasar Laporan Keuangan. (Adipramono, Ed.) (Edition 1). Jakarta: PT. Grasindo, Anggota IKAPI.

Hery. (2017). Analisis Laporan Keuanagan. (Adipramono, Ed.) (2nd ed.). Jakarta: PT. Grasindo Jl. Palmerah Barat 33-37 , Jakarta 10270.

Hutang, P. K., \& Dan, S. M. (2015). MANUFAKTUR BARANG KONSUMSI YANG TERDAFTAR Salah satu solusi mempertahankan posisi perusahaan untuk terus dapat beroperasi dalam mengantisipasi kondisi keuangan yang terkadang tidak mampu untuk kita prediksi , adalah dengan memanajemen keuangan agar mampu, $X(2)$.

Indonesia, I. B. (2018). Bisnis Kredit Perbankan (Kedua). Jakarta.

Ingga, I. (2017). Akuntansi Manajemen: Implementasi Dalam Kasus Indonesia. Yogyakarta.
Kariyoto. (2018). Manajemen Konsep dan Implementasi. Jakarta.

Maith, H. A. (2013). Analisis Laporan Keuangan Dalam Mengukur Kinerja Keuangan Pada Pt. Hanjaya Mandala Sampoerna Tbk. Jurnal EMBA, 1(3), 619-628.

Periode, B. E. I., Kurniawan, D., Nugroho, P. I., \& Kristanto, A. B. (2013). PENGARUH AKTIVITAS OPERASI TERHADAP CASH RATIO DAN CASH CYCLE PADA SEKTOR INDUSTRI BARANG KONSUMSI YANG TERDAFTAR DI.

Perusahaan, T. P., Bei, D. I., \& Tahun, P. (2013). No Title.

Prihadi, T. (2013). Analisis Laporan Keuangan: Teori dan Aplikasi. Jakarta.

Riswan, \& Kesuma, Y. F. (2014). Analisis Laporan Keuangan Sebagai Dasar Dalam Penilaian Kinerja Keuangan Pt. Budi Satria Wahana Motor. Jurnal Akuntansi \& Keuangan, 5(1), 93-121.

Rudi, I. (2012). Pengaruh Hutang terhadap Profitabilitas Perusahaan Telekomunikasi yang Go Public di BEI Periode 2006-2011.

Setyowati, M. S. (2016). Pengantar Akuntansi 2. Jakarta.

Sjahrial, D. (2013). Pengantar

Copyright (c) 2020 Dyah Ayu Retno Inten, SE., M.Si.

This work is licensed under a Creative Commons Attribution-NonCommercial-ShareAlike 4.0 International License. 
Manajemen Keuangan. Jakarta.

Sugiono, A. (2016). Panduan Praktis

Dasar Analisis Laporan

Keuangan. Jakarta.

Tinggi, S., Ekonomi, I., \& Wiwaha, W. (n.d.). IE Ja W ng id an ya P Wi la w gi a at ha Ja W ng id an ya $\mathrm{P}$ Wi la w gi a at ha.

Wahyudiono, B. (2014). Mudah Membaca Laporan Keuangan. Jakarta.

Wijaya, D. (2017). Manajemen Keuangan Konsep dan Penerapannya. Jakarta. 